
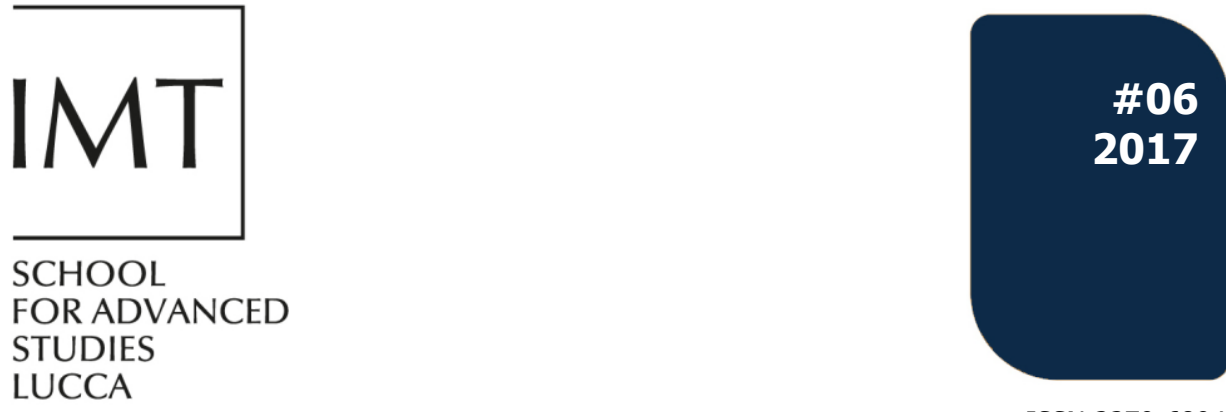

ISSN 2279-6894 IMT LUCCA EIC WORKING PAPER SERIES 06

\title{
School Infrastructure Spending and Educational Outcomes in Northern Italy
}

Alessandro Belmonte

Vincenzo Bove

Giovanna D'Inverno

Marco Modica 


\section{School Infrastructure Spending and Educational Outcomes in Northern Italy}

\section{Alessandro Belmonte}

IMT School for Advanced Studies Lucca

\section{Vincenzo Bove}

University of Warwick

\section{Giovanna D'Inverno}

IMT School for Advanced Studies Lucca

\section{Marco Modica}

CNR IRCrES 


\title{
School Infrastructure Spending and Educational Outcomes in Northern Italy*
}

\author{
Alessandro Belmonte \\ Vincenzo Bove \\ IMT Alti Studi Lucca \\ University of Warwick \\ Giovanna D'Inverno \\ Marco Modica \\ IMT Alti Studi Lucca \\ CNR IRCrES
}

\begin{abstract}
We explore whether investment in public school infrastructure affects students' achievement. We use data on extra funding to public high schools after the 2012 Northern Italy earthquake and apply a quasi-experimental design and an instrumental variable strategy. We find that spending on school infrastructure increases standardized test scores in mathematics and Italian language, and the effect is stronger for lower-achieving students and in mathematics. These results provide evidence in favor of a positive impact of capital spending in improving the learning environment and performances of high school students.
\end{abstract}

Keywords: education; school infrastructure spending; high school. JEL Classification: I22, I24, H75.

${ }^{*}$ We thank Leandro Elia, Paolo Pinotti and participants at the 4th Workshop on the Efficiency in Education at the Polytechnic University of Milan and at the 3rd Workshop on Educations Economics in Leuven. The responsibility for any remaining errors or omissions is our own. Part of this article was written while Alessandro Belmonte was at Invalsi. 


\section{Introduction}

Whether or not school spending has an impact on student outcomes has been highly debated in the last sixty years in the economics literature (Card \& Krueger, 1996). The debate roots from the so-called Coleman Report, published by the US Government in 1966. Coleman's (1966) main conclusion was that school funding does not play a central role in determining students' achievement, giving rise to a wealth of studies on the link between resources and educational outcomes (see e.g., Neilson \& Zimmerman, 2014; Jackson et al. , 2016). Overall, there is a lack of agreement on the impact of funding on students' performances. Whereas in a meta-analysis Greenwald et al. (1996, p.384) conclude that "school resources are systematically related to student achievement and that these relations are large enough to be educationally important," many subsequent studies find little or no effect (see e.g., Hanushek, 1996; Card \& Krueger, 1996).

This disagreement is perhaps not very surprising as most of these studies face severe difficulties in attempting to unravel a causal relationship between school spending and educational outcome. Counterfactual outcomes are sensitive to the choice of the estimator and the identification strategy to address the endogeneity of school resources. Although previous studies have used a variety of methodological approaches to deal with the joint determination of educational inputs and outputs, modest estimated effects of school spending could be a consequence of unresolved endogeneity biases (see Jackson et al. 2016). At the same time, studies often explore very heterogeneous inputs of the educational production process. Jones \& Zimmer (2001) note that most of the literature focuses on school-specific inputs, school organization inputs (e.g., class size), environmental characteristics and socioeconomic (family) characteristics, but neglect capital inputs such as school infrastructure. In fact, there are only a handful of studies on the school infrastructure-students' learning relationship and they focus preponderantly on the US School System. Aaronson \& Mazumder (2011) investigate the impact of the so-called "Rosenwald initiative" in the US between 1914 and 1931 and find that substantial improvements to school quality and access in relatively deprived environments are followed by large productivity gains. Neilson \& Zimmerman (2014) find strong evidence that school construction programs led, among other outcomes, to sustained gains in reading scores for elementary and middle school students. Yet, Martorell et al. (2016), who focuses more specifically on school facility investments, find little evidence that spending on facilities generate improvements in student achievement.

Against this background, we explore whether spending on physical infrastructure affects test scores in mathematics and Italian language using data 
on Italian public high schools. To handle the endogeneity of idiosyncratic changes in school funding, we use two strategies. First, we employ a quasiexperimental design and make use of information on the extra funding that a specific group of schools received in the aftermath of the 2012 Northern Italy earthquake. In May 2012, two major earthquakes in Northern Italy caused considerable damages to public buildings and prompted specific interventions for the mitigation of seismic risk. As a result, a large number of undamaged schools, but close enough to the areas hit by the earthquake, received large extra funds to modernize and improve the quality of their buildings as well as their resilience to the earthquakes. We compute the differential effect of receiving extra funds on the treatment group, i.e., undamaged schools outside the earthquake area, that were awarded special funding, versus a control group of schools in neighboring municipalities. The schools in the control group are in areas sufficiently far from the earthquake epicenter and at low risk of future seismic activities; therefore these schools are both undamaged as well as unfunded. This strategy allows us to estimate whether being a recipient of funding increases students' achievement. Second, to evaluate the elasticity of test scores with respect to funding, we implement an instrumental variables (IV) identification strategy. In particular, we use seismic hazard maps and exploit exogenous values of peak ground acceleration (henceforth PGA), which explain much of the variation in the amount of the received funding. Taken together, our results suggest that improving the quality of school buildings has a positive effect on students' achievements. Moreover, we find that low-achieving students benefit the most from improved physical infrastructure.

\section{Data}

\subsection{The 2012 Northern Italy earthquake and school funding}

Deciphering the impact of school resources on achievements is complicated by the fact that students' performance and the selection of funded schools, or the spending levels, are potentially simultaneously determined. We address this issue by using data on school funding provided after a natural disaster. On May 20, 2012 an earthquake of magnitude 6.1, followed by a second one on May 29, hit a territory of 3.5 thousands squared kilometers in the Northern part of Emilia-Romagna, a region near the borders with Veneto and Lombardia. Before the 2012 seismic events, this area was generally not 
considered at risk of seismic activities 1

In the aftermath of the earthquake, the Italian government made available more than 24.4 millions of euros to several public buildings in the affected municipalities, including 276 high schools, with the aim of reconstructing damaged buildings, renewing and maintaining all school buildings as well as keeping undamaged buildings safe from future seismic threats. In fact, this extra funding was given to both damaged schools as well as to schools considered at risk for earthquakes in the future. We use several legislative acts to assemble data on the amount of extra funding to public schools in the region 2 As the earthquake could have had a direct effect on the learning environment and on students' performances, we use information on the volume of damaged buildings in each municipality, as estimated by the INGV (National Institute of Geophysics and Volcanology) in the aftermath of the seism using a microseismic survey $]^{3}$ Then, for our empirical analysis we select only municipalities where "no damage" was reported by the INGV assessment.

In more details, we collect data for a total of 236 municipalities, as shown on the map in Figure 1. Out of 236, 69 are discarded as they had a level of damage greater than 0 , on a scale between 0 "no damage" and 5 "destruction" (see grey shaded areas in Figure 1). Out of the 167 remaining municipalities, only 43 have at least one school, for a total of 173 schools (white dots in Figure 1 ). The treated schools are those located in treated municipalities (shaded areas in Figure 1) and make up a good portion of the total number of schools, $39 \%$ (68). Although these schools reported no damage, they received about 3.6 millions of euros to improve the quality of their buildings. Summary statistics, reported in Table A.1 in the appendix, show that these schools received on average about 1,000 euros per student. This is an exceptional amount of funding, as the average total spending per student in Italy in 2013 was only 9,174 euros; perhaps most importantly, however, capital spending was less than 184 euros in the same year, which makes this extra funding a very large intervention (see OECD, 2016). Our control group is made up

\footnotetext{
${ }^{1}$ With the exception of the seismic sequence of Ferrara in 1570, Argenta in 1624 and Bologna in 1929 (Vannoli et al. 2015), few other small intensity earthquakes had had an impact on its inhabitants' collective memory. As a result, the perception of a seismic risk was comparably very small relative to the rest of Italy. In fact, PGA values in this area are, on average, only $20 \%$ of those characterizing the nearby Apennine mountain chain. See http://zonesismiche.mi.ingv.it/

${ }^{2}$ Starting from June 2012, the deputy commissioner enacted a series of legislative acts with guidelines for securing school buildings as well as criteria to assign available funds. See http://www.regione.emilia-romagna.it/terremoto/gli-atti-per-la-ricostruzione/2012. A list of funds awarded in Emilia-Romagna is available at http://bur.regione.emiliaromagna.it/dettaglio-inserzione?i=e859a4a07037459a9547ab738738c751.

${ }^{3}$ See Appendix A.1 for a through description of the microseismic survey.
} 
of 105 schools that received no funding and they were not affected by the earthquake, but they are located in municipalities proximate to the treated areas (i.e., they either share borders with the treated areas or there is no more than one municipality between them and the treated areas, see dashed areas in Figure 1).

The map also contains information on the PGA values, gathered from the INGV database. The color bar shows the gradient of PGA for each municipality, from low to high. PGA is the maximum ground acceleration during earthquakes and it is commonly used as an index for seismic hazard, the probability that an earthquake will occur in a specific geographic area. In our sample, the PGA varies between 0.087 and 0.207 , with an average intensity of 0.155 . The amount of extra funding per student in the treated areas was mostly driven by the necessity of safeguarding school buildings, in areas close enough to the earthquake crater, from future seismic threats and minimize potential damages to school infrastructure, hence is a function, among other things, of PGA levels.4

\section{$2.2 \quad$ Test scores}

Information on test scores is taken from the Italian National Institute for the Evaluation of the Educational System (INVALSI). Since the academic year 2010/2011, tenth graders in Italian high schools take standardized assessments on the same day (May 9). The participation of all public schools is compulsory and the assessment encompasses only mathematics and Italian language skills. Our dependent variable is the percentage of correct answers for each high school. From the same database, we also take information on school size and on the shares of male and native students in each school 5 For each school, we also compute average test scores for low-achieving and high-achieving students, the fraction of students in the 5th/10th percentile of the score distribution and in the $90 \mathrm{th} / 95 \mathrm{th}$ percentile, respectively. We assemble school-level annual data over six academic years, from 2011 to 2016.

\footnotetext{
${ }^{4}$ See the first decrees enacted by the deputy commissioner, i.e., ODC \#2 (16 June 2012) and the ODC \#4 (3 July 2012).

${ }^{5}$ We refer the interested reader to Angrist et al. (2014) and Battistin \& Meroni (2016) for a thorough description of the test and a more comprehensive overview than we can possibly give here. Battistin \& Meroni (2016) also offer a novel study on instruction time and students' performance in Italy, using the same data.
} 


\section{Empirical strategy}

Our identification strategy is twofold. First, we use the quasi-experimental setting induced by the 2012 Northern Italy earthquake to get a handle on the direction of causation in the infrastructure spending - students' achievement relationship. Using information from the map in Figure 1, we can measure the impact of receiving additional resources on test scores by comparing the evolution of test scores before and after the policy introduction in the areas exposed to this policy as compared to those that were not. We use a simple empirical research design, a difference-in-differences estimation strategy, which takes the following form:

$$
\begin{aligned}
\log y_{i t} & =\alpha_{0}+\alpha_{1} D_{i}+\alpha_{2} P_{t-1}+\alpha_{3} D_{i} * P_{t-1}+X_{i t}^{\prime} \alpha_{4}+ \\
& +\mu_{i}+\eta_{p} * P_{t}+\theta \text { Trend }+\varepsilon_{i t}
\end{aligned}
$$

where the outcome variable $y_{i t}$ denotes the average test score in either mathematics or Italian language in school $i$ in year $t ; D_{i}$ is a dummy that takes value one if the school belongs to the treated area; $P_{t}$ is a dummy that takes value one if the observation is in the post-treatment period (i.e., post 2012) ${ }^{6} X_{i t}$ is a vector of school covariates which includes school size and the shares of male and native students in each school; $\mu_{i}$ is the school fixed effect, which absorb school-specific constant (or slow-moving) features; as provinces could have implemented local interventions after the earthquake, we interact province fixed effect $\eta_{p}$ with $P_{t}$ to control for province-specific policies after $2012 \sqrt{7} \theta$ is the coefficient of a school-specific time trend variable and $\varepsilon_{i t}$ is an error or disturbance term. $D_{i} * P_{t}$ is the interaction between the treatment schools $D_{i}$ and $P_{t}$, the dummy variable equal to one in the post-treatment period; therefore, $\alpha_{3}$ is our parameter of interest, the difference-in-differences estimates of the impact of receiving funding on students' achievement. Note that, for small values of the coefficient, $100^{*} \alpha_{3}$ can be interpreted as the percentage increase in the test score when schools receive extra funding.

Second, we want to offer estimates of the elasticity of test scores with respect to spending per capita. Yet, as noted above, idiosyncratic changes in school spending are likely endogenous as the amount of funding allocated to each school can be correlated with unobservable school-level characteristics. To quantify this relation, we estimate 2SLS models where we instrument for

\footnotetext{
${ }^{6}$ We lag the treatment by one year to allow time for the funding to be invested.

${ }^{7} \mathrm{~A}$ province is an administrative division between a municipality and a region, and constitute the third NUTS administrative level. Provinces have, among other functions, the local planning and the coordination of schools activities. In our sample, we have a total of 10 provinces.
} 
school spending with the values of peak ground acceleration (PGA), the maximum ground acceleration during the earthquakes. Recall that funding was allocated to schools to improve the resilience of their buildings to earthquakes and more funding per capita was granted to schools in municipalities with higher earthquake risks. The proposed instrument is thus strongly correlated with school funding. At the same time, it is uncorrelated with school-level unobservables that might affect test scores. Thus, PGA offers a valid instrument.

The second stage of the IV estimation is given by:

$$
\log y_{i t}=\beta_{0}+\beta_{1} \widehat{F U N D}_{i t-1}+X_{i t}^{\prime} \beta_{2}+\mu_{i}+\eta_{p} * P_{t}+\theta \text { Trend }+\varepsilon_{i t}
$$

where the outcome variable $y_{i t}$, the vector of controls at the school level, the trend variables and the fixed effects are the same as in equation (1). $\widehat{F U N D}_{i t}$ is the estimated funding per pupil as predicted by the first stage. The equation we estimate in the first stage uses the PGA level in the area where the school is located as an instrument for actual funding. Given the log-linearity of the model, the interpretation of $\beta_{1}$ is that of a proportional change in the test score given a unit change in funding, holding all else constant.

\section{Results}

In Table 1 we present the relation between funding and student scores in mathematics, whereas in Table 2 we focus on Italian language. In column 1 of each table we report the average score for all students, in columns 2 and 3 the test scores for students in the 5th and 10th percentile of the score distribution (i.e., low-achieving students), and in columns 4 and 5 the test scores for students in the 90th and 95th percentile (i.e. high-achieving students).

In panels $\mathrm{A}$ we show a naive OLS estimation, which reveals a positive correlation between funding per pupil and test scores.If for purely illustrative purposes one interprets the OLS estimates as causal, then, according to the estimates, a one-unit increase in school infrastructure spending per student (that is, 100 euro) is associated with an estimated increase in test scores in mathematics in the range of $0.2 \%$ to $1.4 \%$, holding all else constant. The relation is insignificant at conventional levels when we replace test scores in mathematics with those in Italian language (Panel A, Table 2) 8

\footnotetext{
${ }^{8}$ Note that all models include the share of males, of native students and the total number of students in each school as well as school fixed effects, time trends and interactions between province fixed effects and post-treatment period dummy. Using linear trends,
} 
In panel B we turn to our quasi-experimental design and we uncover a positive effect of receiving extra funding on test scores, although the relation is still not significantly different from zero for Italian language. In more details, test scores will increase by $10 \%$ overall if a school is a recipient of funding, and the effect is substantially larger for low-achieving students (between $26 \%$ and $33 \%$ ).

Turning to the elasticity of student outcomes with respect to the amount of resources devoted to school Infrastructure, recall that in Panel A our main coefficients of interest is most certainly contaminated by endogeneity from uncontrolled confounding variables. Therefore in panel $\mathrm{C}$ we turn to the estimated coefficient of school funding in the second stage of our 2SLS. We use the PGA, an index of seismic hazard, as exogenous instrument. As we can see, the coefficients are now substantially larger than those of the naive regressions in panel $\mathrm{A}$ and they are all statistically different from zero. Distributing an extra 100 euro per pupil to schools will produce an estimated test score gains in mathematics in the range of $1.5 \%$ to almost $13 \%$. Again, we find that the marginal return to investment in school infrastructure is greater the lower the quality of the students. Interestingly, we now obtain similar results with test scores in Italian language and the estimated magnitudes of the relationship between funding and students' achievement are not only statistically significant but also economically meaningful.

In panel $\mathrm{D}$ we show the reduced form and the first stage estimates. As expected, in the reduced form we find that an increase in the PGA level leads to a higher amount of infrastructure funding received by the school. At the same time, the first stage reveals that the PGA level has a sizeable impact on school funding. We report the Kleinbergen-Paap F-Statistic, which is similar to the conventional F-statistic, but takes into account the clustering of the standard errors. The values are all above conventional levels characterizing weak instruments.

To dig deeper into the relationship between school funding and students' standardized test scores, Figure 2 shows the relation between the estimated coefficient $\beta_{1}$ in equation (2) and the quantiles of the distribution of the test scores. As the figure clearly reveals, allocating additional funding to schools' infrastructure has higher marginal effects on the achievement of students with the lowest scores on the standardized tests. Whereas in Italian language the pattern is less clear-cut, in mathematics the estimated effect decreases monotonically as we move from the 10th to the 90th percentile of the standardized test score distribution. Results are overall similar when we look at relation

quadratic trends, cubic polynomial in time (i.e., $t, t^{2}$, and $t^{3}$ ) or year dummies produce similar results. 
between the estimated coefficient $\alpha_{3}$ in equation (1) and the quantiles of the distribution of test scores (see Figure A1). We can conclude from these two tables that the previous results using a difference-in-differences approach are strongly borne out by this new set of empirical results. The effect of school funding on students' achievement is overall quantitative large, statistically significant and robust, in particular in mathematics and for low-achieving students.

\section{Conclusion}

In this research note we explore the impact of school infrastructure investments on students' achievement. We use data on school funding provided after a natural disaster, a magnitude 6.0 earthquake that hit the Northern part of Emilia Romagna region in May 2012, affecting an area of 3,500 squared kilometers. We use information on the allocation process (whether schools received funding or not) and on the amount of funding that each school received (function of pre-determined seismic risks) to implement two intertwined yet different identification strategies, so as to give our regression estimates a causal interpretation.

Our empirical results provide evidence in favor of a positive and quite large return of school infrastructure spending on students' education. As such, this study outlines the role of physical capital spending in improving the learning environment of tenth graders and offers potential policy prescriptions for investing in school infrastructure.

There are important limitations that we are unable to address in this note. We do not have information on how exactly buildings were improved after receiving the extra funding; therefore we do not know what are the underlying causal mechanism linking better infrastructures to test score gains. As Martorell et al. (2016) outlined in their contribution, there might be several, potential mechanisms at play such as the improvement in temperature control; modernization in infrastructure to support the latest technology or labs for science education; infrastructure enhancements to avoid chronic distractions and reduce the number of missed school days. Low-quality facilities could also undermine effort, especially of low-achieving students. In fact, whereas it is plausible that low-achieving students display higher marginal returns to investment in schooling than high-achieving students, we still do not know what exactly makes them more likely to benefit from an improvement in physical environment of schools. Yet, because of the limited number of empirical works on how school infrastructure spending affects educational outcomes and the lack of consensus on a number of key questions, there is 
definitely a busy agenda for future research in this area.

\section{References}

Aaronson, Daniel, \& Mazumder, Bhashkar. 2011. The impact of Rosenwald schools on black achievement. Journal of Political Economy, 119(5), 821-888.

Angrist, Joshua D., Battistin, Erich, \& Vuri, Daniela. 2014 (May). In a Small Moment: Class Size and Moral Hazard in the Mezzogiorno. Working Paper 20173. National Bureau of Economic Research.

Battistin, Erich, \& Meroni, Elena Claudia. 2016. Should we increase instruction time in low achieving schools? Evidence from Southern Italy. Economics of Education Review, $\mathbf{5 5}, 39-56$.

Card, David, \& Krueger, Alan B. 1996. School Resources and Student Outcomes: An Overview of the Literature and New Evidence from North and South Carolina. The Journal of Economic Perspectives, 10(4), 31-50.

Coleman, James Samuel. 1966. Equality of Educational Opportunity. Government Printing Office, Washington.

Greenwald, Rob, Hedges, Larry V, \& Laine, Richard D. 1996. The effect of school resources on student achievement. Review of educational research, 66(3), 361-396.

Hanushek, Eric A. 1996. Measuring investment in education. The Journal of Economic Perspectives, 10(4), 9-30.

Jackson, C Kirabo, Johnson, Rucker C, \& Persico, Claudia. 2016. The Effects of School Spending on Educational and Economic Outcomes: Evidence from School Finance Reforms. The Quarterly Journal of Economics, 157, 218.

Jones, John T, \& Zimmer, Ron W. 2001. Examining the impact of capital on academic achievement. Economics of Education Review, 20(6), 577-588.

Martorell, Paco, Stange, Kevin, \& McFarlin, Isaac. 2016. Investing in schools: capital spending, facility conditions, and student achievement. Journal of Public Economics, 140, 13-29.

Neilson, Christopher A, \& Zimmerman, Seth D. 2014. The effect of school construction on test scores, school enrollment, and home prices. Journal of Public Economics, 120, $18-31$.

Vannoli, Paola, Burrato, Pierfrancesco, \& Valensise, Gianluca. 2015. The seismotectonics of the Po Plain (northern Italy): Tectonic diversity in a blind faulting domain. Pure and Applied Geophysics, 172(5), 1105-1142. 
Figure 1: Treated and control areas

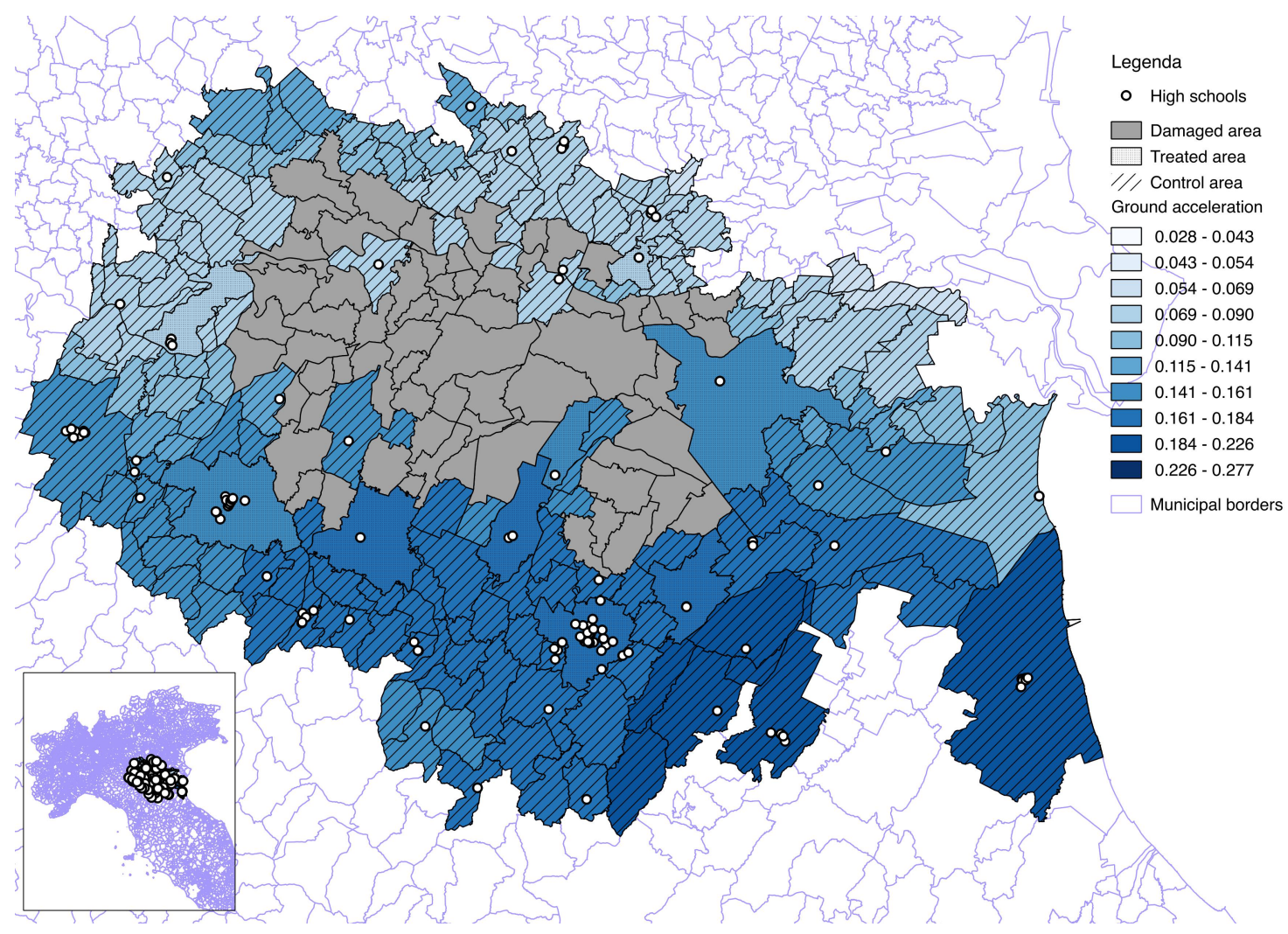


Figure 2: Estimated impact of school funding on test scores by quantiles of the distribution of test scores

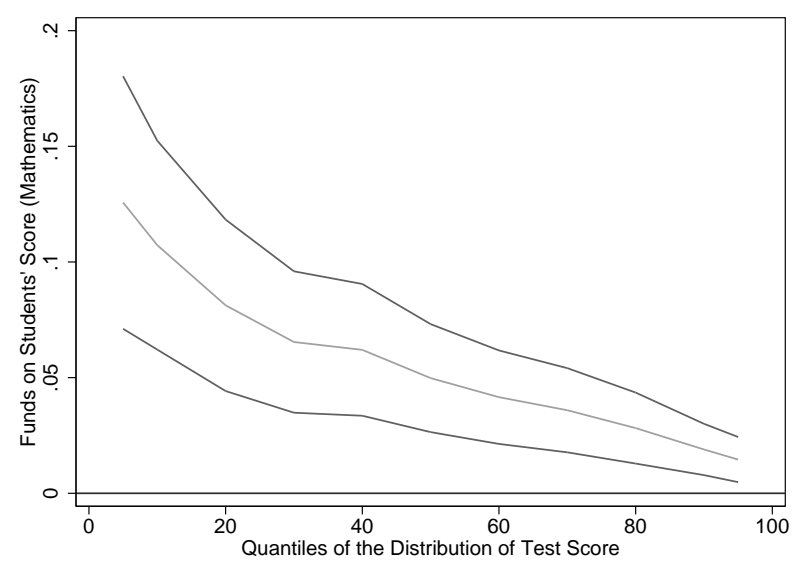

(a) Mathematics

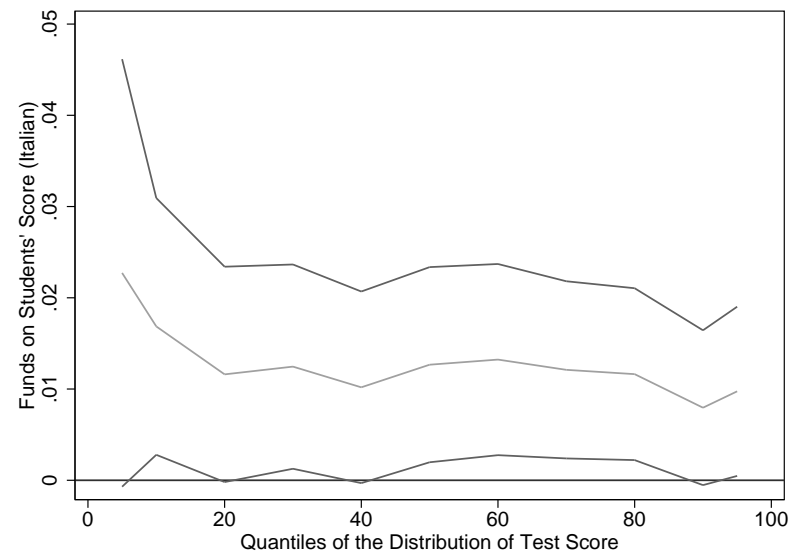

(b) Italian Language 
Table 1: Secondary School, Mathematics: funding and students scores

\begin{tabular}{|c|c|c|c|c|c|c|}
\hline & $\begin{array}{c}(1) \\
\text { Score (mean) }\end{array}$ & $\begin{array}{c}(2) \\
\text { Score }(\mathrm{p} 5)\end{array}$ & $\begin{array}{c}(3) \\
\text { Score }(\mathrm{p} 10)\end{array}$ & $\begin{array}{c}(4) \\
\text { Score (p90) }\end{array}$ & $\begin{array}{c}(5) \\
\text { Score (p95) }\end{array}$ & $\begin{array}{c}6) \\
\text { Funding p.c. }\end{array}$ \\
\hline \multicolumn{7}{|c|}{ Panel A OLS Estimation. } \\
\hline Funding p.c. & $\begin{array}{c}0.003^{* * *} \\
(0.001)\end{array}$ & $\begin{array}{l}0.014^{* *} \\
(0.005)\end{array}$ & $\begin{array}{l}0.010^{* *} \\
(0.004)\end{array}$ & $\begin{array}{l}0.002^{* *} \\
(0.001)\end{array}$ & $\begin{array}{c}0.003^{* * *} \\
(0.001)\end{array}$ & \\
\hline \multicolumn{7}{|c|}{ Panel B OLS Estimation. } \\
\hline Spending dummy & $\begin{array}{c}0.099^{* * *} \\
(0.024)\end{array}$ & $\begin{array}{c}0.329^{* * *} \\
(0.094)\end{array}$ & $\begin{array}{c}0.262^{* * *} \\
(0.063)\end{array}$ & $\begin{array}{l}0.043^{* *} \\
(0.021)\end{array}$ & $\begin{array}{l}0.040^{*} \\
(0.021)\end{array}$ & \\
\hline \multicolumn{7}{|c|}{ Panel C IV Estimation - Second Stage. } \\
\hline Funding p.c. & $\begin{array}{c}0.046^{* * *} \\
(0.011)\end{array}$ & $\begin{array}{c}0.126^{* * *} \\
(0.028)\end{array}$ & $\begin{array}{c}0.107^{* * *} \\
(0.023)\end{array}$ & $\begin{array}{c}0.019^{* * *} \\
(0.006)\end{array}$ & $\begin{array}{l}0.015^{* * *} \\
(0.005)\end{array}$ & \\
\hline KP F-Statistic & 18.522 & 18.522 & 18.522 & 18.522 & 18.522 & \\
\hline \multicolumn{7}{|c|}{ Panel D Reduced Form and First Stage. } \\
\hline Seismic hazard & $\begin{array}{c}1.204^{* * *} \\
(0.101)\end{array}$ & $\begin{array}{l}3.284^{* * *} \\
(0.441)\end{array}$ & $\begin{array}{c}2.803^{* * *} \\
(0.291)\end{array}$ & $\begin{array}{c}0.495^{* * *} \\
(0.093)\end{array}$ & $\begin{array}{c}0.381^{* * *} \\
(0.099)\end{array}$ & $\begin{array}{c}26.128^{* * *} \\
(6.070)\end{array}$ \\
\hline Observations & 692 & 692 & 692 & 692 & 692 & 692 \\
\hline$N_{i}$ & 173 & 173 & 173 & 173 & 173 & 173 \\
\hline
\end{tabular}

Notes: School Fixed-effect models. All regressions include fraction of males, fraction of native students, and number of students in the tenth cohort as well as linear trend and province dummies interacted with $P_{t}$. Standard errors are clustered at the school level. ${ }^{*} p<0.10,{ }^{* *} p<0.05,{ }^{* * *} p<0.01$. 
Table 2: Secondary School, Italian: funding and students scores

\begin{tabular}{|c|c|c|c|c|c|c|}
\hline & $\begin{array}{c}(1) \\
\text { Score (mean) }\end{array}$ & $\begin{array}{c}(2) \\
\text { Score }(\mathrm{p} 5)\end{array}$ & $\begin{array}{c}(3) \\
\text { Score }(\mathrm{p} 10)\end{array}$ & $\begin{array}{c}(4) \\
\text { Score (p90) }\end{array}$ & $\begin{array}{c}(5) \\
\text { Score (p95) }\end{array}$ & $\begin{array}{c}6) \\
\text { Funding p.c. }\end{array}$ \\
\hline \multicolumn{7}{|c|}{ Panel A OLS Estimation. } \\
\hline Funding p.c. & $\begin{array}{c}0.001 \\
(0.001)\end{array}$ & $\begin{array}{c}0.005 \\
(0.006)\end{array}$ & $\begin{array}{c}0.002 \\
(0.003)\end{array}$ & $\begin{array}{c}0.000 \\
(0.001)\end{array}$ & $\begin{array}{c}0.000 \\
(0.001)\end{array}$ & \\
\hline \multicolumn{7}{|c|}{ Panel B OLS Estimation. } \\
\hline Spending dummy & $\begin{array}{c}0.020 \\
(0.022)\end{array}$ & $\begin{array}{c}0.073 \\
(0.064)\end{array}$ & $\begin{array}{c}0.051 \\
(0.042)\end{array}$ & $\begin{array}{c}0.008 \\
(0.019)\end{array}$ & $\begin{array}{c}0.005 \\
(0.019)\end{array}$ & \\
\hline \multicolumn{7}{|c|}{ Panel C IV Estimation - Second Stage. } \\
\hline Funding p.c. & $\begin{array}{l}0.012^{* *} \\
(0.005)\end{array}$ & $\begin{array}{l}0.023^{*} \\
(0.012)\end{array}$ & $\begin{array}{l}0.017^{* *} \\
(0.007)\end{array}$ & $\begin{array}{l}0.008^{*} \\
(0.004)\end{array}$ & $\begin{array}{l}0.010^{* *} \\
(0.005)\end{array}$ & \\
\hline KP F-Statistic & 15.841 & 15.841 & 15.841 & 15.841 & 15.841 & \\
\hline \multicolumn{7}{|c|}{ Panel D Reduced Form and First Stage. } \\
\hline Seismic hazard & $\begin{array}{c}0.328^{* * *} \\
(0.113) \\
\end{array}$ & $\begin{array}{l}0.623^{*} \\
(0.345)\end{array}$ & $\begin{array}{l}0.462^{* *} \\
(0.197)\end{array}$ & $\begin{array}{l}0.218^{* *} \\
(0.106)\end{array}$ & $\begin{array}{l}0.267^{* *} \\
(0.109)\end{array}$ & $\begin{array}{c}27.413^{* * *} \\
(6.887)\end{array}$ \\
\hline Observations & 696 & 696 & 696 & 696 & 696 & 696 \\
\hline$N_{i}$ & 173 & 173 & 173 & 173 & 173 & 173 \\
\hline
\end{tabular}

Notes: School Fixed-effect models. All regressions include fraction of males, fraction of native students, and number of students in the tenth cohort as well as linear trend and province dummies interacted with $P_{t}$. Standard errors are clustered at the school level. ${ }^{*} p<0.10,{ }^{* *} p<0.05,{ }^{* * *} p<0.01$. 


\section{A Online Appendix}

\section{A.1 The earthquake and the INGV microseismic sur- vey}

Generally, after an earthquake, first responders are also responsible for collecting the intensity values of the earthquake for the damaged localities, both in terms of European Macroseismic Scale (EMS-98) and Mercalli-Cancani-Sieberg macroseismic scale, MCS (see for more details Grünthal, 1998 and Sieberg, 1930). For Italy this is commonly done by the Italian Civil Protection Department (DPC) supported by other institutions such as the National Research Council (CNR) or the National Institute of Geophysicss and Volcanology (INGV).

The macroseismic survey for the 2012 Northern Italy earthquake, was performed initially adopting the MCS scale (according to the Italian macroseismic database, DBMI11) also in order to provide a quick way to estimate the damage distribution of the earthquake over the entire territory. Subsequently, the macroseismic intensity values are reported in terms of EMS-98 scale by the knowledge of the percentage of the damaged buildings and their vulnerability in each locality. The results of the survey are provided in Galli et al., 2012 .

Then, by knowing macroseismic intensity values in EMS-98 scale and the level of vulnerability of buildings, it is possible to estimate the damage of the buildings of any single area according to a method proposed by Bernardini et al. (2007). Indeed, according to the EMS-98 scale, buildings are grouped into 6 classes of vulnerability (A, highest vulnerability, to $\mathrm{F}$ ) in relation to the structural characteristics of the buildings (e.g. typological and morphological information and age of construction of the buildings) and it defines 5 levels of increasing damage (from D1 to D5, where D0 means no damage).

Operationally, the intensity value is provided by DPC together with the vulnerability level of buildings (coming from the information provided by the census of 2011) and both are known at a very low level, namely a census tract. In this way it is possible to calculate the damage grade (D0 to D5) for each area according to the EMS-98 damage probability matrices provided by Gränthal, 1998. As an example, if a locality is classified with intensity IX (EMS-98 scale) it returns that many buildings with medium vulnerability level (class B) are heavily damaged (D4) as well as few buildings of vulnerability level C, while most buildings with high vulnerability level (class A) are completely collapsed (D5). Then, according to Bernardini et al., 2007 it is possible to express in a fuzzy way (e.g. allowing for a numerical quantification) the linguistic expressions 'few', 'many', 'most'. This allows to define a damage probability matrices, one for each vulnerability class of the buildings. In the epicentral area, because of the jointly effect of moderate magnitude of the earthquake and the characteristics of buildings, most of these have experienced no damage (D0) or light damage (D1).

\section{A.2 Tables and Figures}


Table A1: Summary Statistics

\begin{tabular}{|c|c|c|c|c|c|}
\hline & mean & sd & $\min$ & $\max$ & count \\
\hline \multicolumn{6}{|c|}{ Panel $A$ - Treatment and IV } \\
\hline Spending dummy & 0.39 & 0.49 & 0.00 & 1.00 & 173 \\
\hline Funding per capita $(00)^{a}$ & 3.89 & 10.29 & 0.00 & 80.65 & 173 \\
\hline Funding per capita $(00)^{b}$ & 9.91 & 14.53 & 0.73 & 80.65 & 68 \\
\hline Seismic hazard (PGA) & 0.16 & 0.03 & 0.09 & 0.21 & 173 \\
\hline \multicolumn{6}{|l|}{ Panel B - Mathematics } \\
\hline Score (mean) & 3.80 & 0.33 & 2.79 & 4.46 & 692 \\
\hline Score (p5) & 3.09 & 0.62 & 0.00 & 4.30 & 692 \\
\hline Score (p10) & 3.28 & 0.50 & 0.00 & 4.32 & 692 \\
\hline Score $(p 90)$ & 4.15 & 0.28 & 3.11 & 4.59 & 692 \\
\hline Score (p95) & 4.22 & 0.26 & 3.11 & 4.59 & 692 \\
\hline \multicolumn{6}{|l|}{ Panel $C$ - Italian Language } \\
\hline Score (mean) & 4.10 & 0.27 & 1.59 & 4.50 & 696 \\
\hline Score $(\mathrm{p} 5)$ & 3.57 & 0.60 & 0.00 & 4.39 & 696 \\
\hline Score (p10) & 3.73 & 0.47 & 0.00 & 4.44 & 696 \\
\hline Score (p90) & 4.34 & 0.20 & 1.59 & 4.58 & 696 \\
\hline Score (p95) & 4.38 & 0.18 & 1.59 & 4.59 & 696 \\
\hline \multicolumn{6}{|l|}{ Panel D-Controls } \\
\hline$\%$ Male & 0.56 & 0.26 & 0.00 & 1.00 & 692 \\
\hline$\%$ Native & 0.82 & 0.14 & 0.21 & 1.00 & 692 \\
\hline Cohort Size & 88.57 & 77.39 & 3.00 & 372.00 & 692 \\
\hline
\end{tabular}

Notes: ${ }^{a}$ All sample. ${ }^{b}$ Only treated. 
Figure A1: Classification of damage to masonry buildings

\begin{tabular}{|c|c|c|}
\hline & Type of Structure & 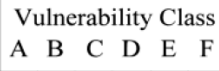 \\
\hline $\begin{array}{l}\frac{\vec{z}}{0} \\
\frac{q_{2}^{2}}{2}\end{array}$ & $\begin{array}{l}\text { rubble stone, fieldstone } \\
\text { adobe (earth brick) } \\
\text { simple stone } \\
\text { massive stone } \\
\text { unreinforced, with } \\
\text { manufactured stone units } \\
\text { unreinforced, with RC floors } \\
\text { reinforced or confined }\end{array}$ & 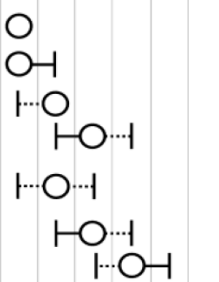 \\
\hline 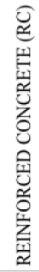 & $\begin{array}{l}\text { frame without } \\
\text { earthquake-resistant design (ERD) } \\
\text { frame with moderate level of ERD } \\
\text { frame with high level of ERD } \\
\text { walls without ERD } \\
\text { walls with moderate level of ERD } \\
\text { walls with high level of ERD }\end{array}$ & 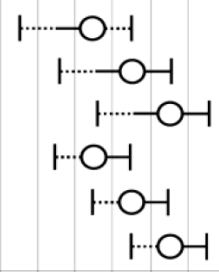 \\
\hline 鼠 & steel structures & $1-0-1$ \\
\hline ळे & timber structures & $1 \cdots-O-1$ \\
\hline
\end{tabular}

(a)

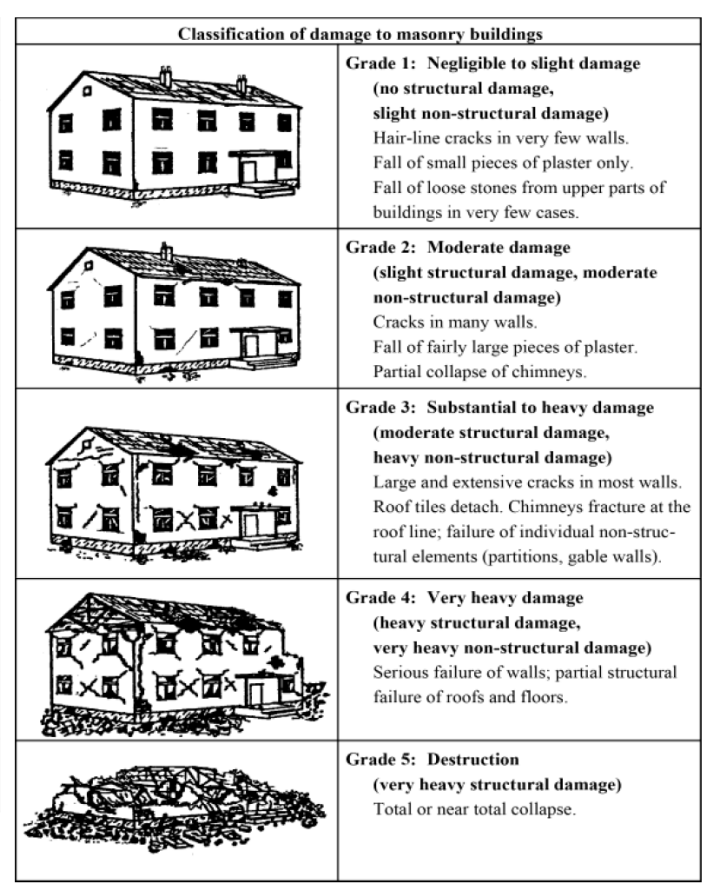

(b) 
Figure A2: Estimated impact of receiving extra-funding on test scores by quantiles of the distribution of test scores

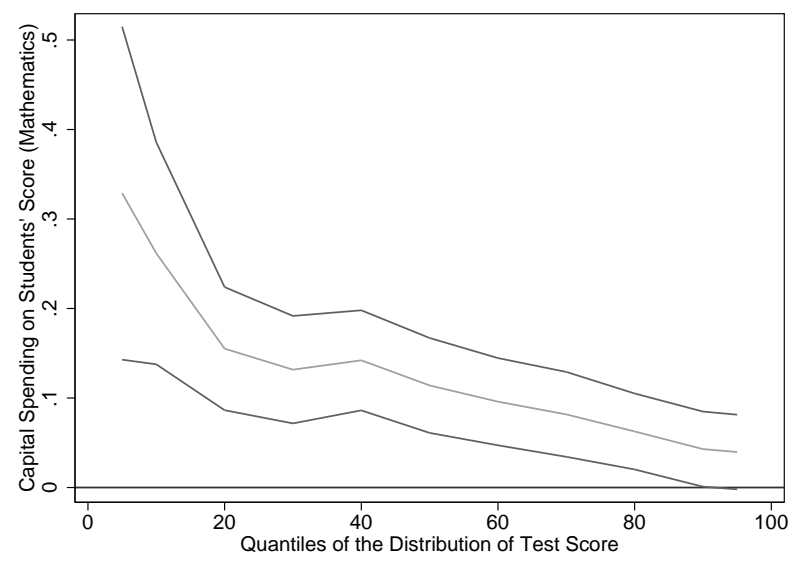

(a) Mathematics

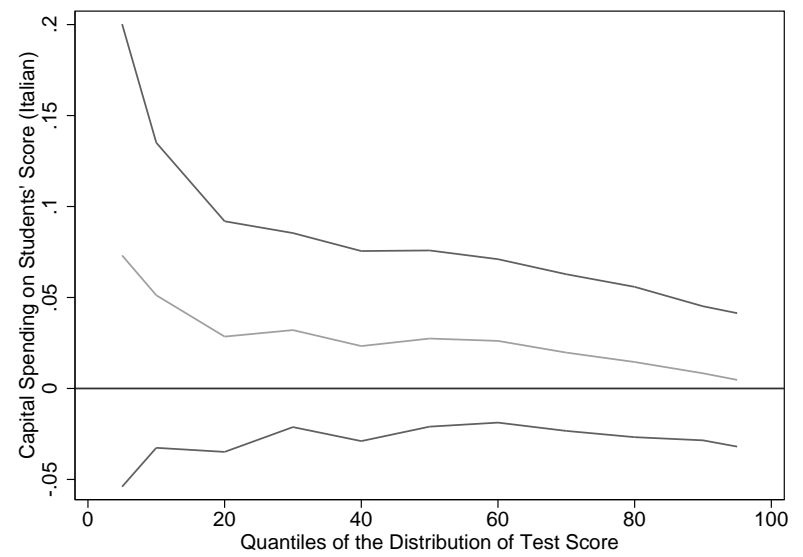

(b) Italian Language 


\section{MTT $\begin{aligned} & \text { SCHOOL } \\ & \text { FOR ADVANCED }\end{aligned}$ STUDIES LUCCA}

2017 @ IMT School for Advanced Studies, Lucca

Piazza San ponziano 6, 55100 Lucca, Italy. www.imtlucca.it 